Research, part of a Special Feature on Resilience Through Multi-scalar Collaboration

\title{
From Resilience to Transformation: the Adaptive Cycle in Two Mexican Urban Centers
}

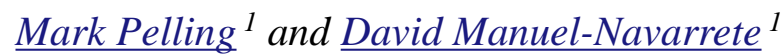

\begin{abstract}
Climate change is but one expression of the internal contradictions of capitalism that include also economic inequality and political alienation. Seen in this way analysis of human responses to climate change must engage with social relations of power. We explore the potential for resilience theory to meet this challenge by applying a framework that integrates the adaptive cycle heuristic and structuration theory to place power at the heart of the analysis and question the transformational qualities of social systems facing climate change. This theoretical frame is applied to Mahahual and Playa del Carmen, two rapidly expanding towns on Mexico's Caribbean coast. The resilience lens is successful in highlighting internal contradictions that maintain social relations of rigidity above flexibility in the existing governance regimes and development pathway. This generates a set of reinforcing institutions and actions that support the status quo while simultaneously undermining long-term flexibility, equitable and sustainable development. One outcome is the placing of limits on scope for adaptation and mitigation to climate change which are externalized from everyday life and development planning alike.
\end{abstract}

Key Words: adaptive cycle; climate change; disaster management; Mexico; power; resilience; transformation

\section{INTRODUCTION}

Climate change is one indication of a lack of sustainability in dominant modes of development (Hulme 2009); other indicators of crisis include global biodiversity loss, the recent global economic crisis and ongoing political alienation (Giddens 2009). The depth of crisis calls for work that can identify pathways for transformation in social systems and by extension social-ecological systems (Harvey 2010), though this has not yet received sufficient attention (Pelling 2011). Within the resilience community, discussion has focused on the fitness of the resilience paradigm as understood in social-ecological systems (SES) theory (Jerneck and Olsson 2008; Nelson 2009). A bias is perceived in application, if not so clearly in theory, for preservation of the status quo in SES approaches. This reflects the empirical heritage of resilience which has been worked out through problems of resource management which are only now beginning to include in analysis wider questions of social and political life (Gelcich et al. 2010). Certainly we know much less about transformation than what makes a system resilient. The literature suggests potential for endogenous social processes to drive transformation and the importance of informal or shadow systems working outside formal organizational or governance structures that provide open space to experiment and learn (Folke et al. 2005; Pelling et al. 2007). Also the role of disaster as a catalyst for social transformation has been recognized (Pelling and Dill 2010). Chapin et al. (2009) see no contradiction between resilience and transformation; a difference in the depth of social change is acknowledged, but resilience remains a core component of transformative potential. To some extent this is a question of scale, as transformation at one level, or indeed in a specific sector of operations, may well support resilience at another scale or in another sector. Within SES theory, the notion of panarchy (Holling et al. 2002) describes this potential for nested systems to be infected by or contain change. Still, there is a lack of theory and few empirical cases with which to explore such relationships and in particular the role of power in shaping when and how transformations occur, who the winners and losers are (Pritchard and 
Sanderson 2002) and implications for adaptive capacity.

With this starting point, we seek to develop resilience theory and in particular build on the adaptive cycle heuristic to help frame an analysis of social transformation, its barriers and motors. We do this by extending Scheffer et al.'s (2002) work on domain transformations which is useful in introducing power analysis interpreted through Giddens' (1984) theory of structuration. The resultant frame is then applied to a comparative analysis of two urban centers that are both facing direct and indirect impacts of climate change in the Mexican Caribbean.

\section{POWER AND THE ADAPTIVE CYCLE}

It has been observed that history proceeds through periods of institutional stability, challenge, crisis, and reorganization, with the possibility for social systems to become locked into any one phase (Handmer and Dovers 1996). This occurs at scales from household formation across the life cycle, to local communities living with economic or other forms of restructuring, and larger political units from municipalities to nation states. Such patterns echo the adaptive cycle proposed by Holling et al. (2002). Here ecological systems pass through phases characterized by conservation (stability), release of nutrients and biomass following disturbance (e.g. a wildfire), reorganization of ecological diversity, and a new round of maturation. The adaptive cycle heuristic not only presents these sequential flows as changes in system state but identifies two axes for their differentiation: connectedness, i.e., internal structural cohesion (high for conservation and release), and potential, accumulated assets (high for conservation and reorganization).

The adaptive cycle offers the possibility of an analytical frame for tracking social systems through sequential stability states and their intervening periods of collapse and reconstruction, but missing is the role of power in determining the character of systems dynamics. If we agree that the majority of contemporary social systems are unsustainable, then understanding how power is held and used is key to understanding how transformation is blocked or may be facilitated. There are many different understandings of power and its use in social systems (Scott 2001). Giddens (1984) presents power as an outcome of the interaction of the agency of individual actors and social structures. Three kinds of structure that frame, yet are the product of agency are identified:

- Structures of legitimation: Institutions (norms and rules) that regulate social interaction and enforce conformity

- Structures of domination: Revealed through control over mechanisms determining resource distribution in society and symbolized by centers of authority

- Structures of signification: Produce interpretations or meanings used to make sense of experience

Bringing the adaptive cycle and Giddens' reading of power together, Scheffer et al. (2002) propose an application of the adaptive cycle heuristic for governance regimes. Figure 1, adapted from Scheffer et al.'s original model, describes four system states and intervening transitional periods.

The cycle can be considered to commence with a state of highly institutionalized stability $(\kappa)$, in which dominant social structures and social agency are well aligned and reinforcing. Change is catalyzed by shock; we are interested in the role played by the identification of novel environmental pressure or its impact, caused by emergent hazard, vulnerability, or changes in risk tolerance with underlying dynamics that can be internal to the system or result from contagion across a policy or geographical boundary or governance scale. If the new pressure is large enough to cause shock then while established social structures of legitimation, domination and signification formally remain, social behavior may begin to de-link, expressed for example, through spontaneous acts of solidarity, dissent, or violence, until the affected components of the system are contained and dominant institutions reassert themselves, or under pressure they become scattered $(\Omega)$. Scatter turns into mobilization $(\alpha)$ when diffuse social action generates its own internal structure, or is massaged into doing so externally in an act of, potentially exploitative, panarchy. Interest groups form as bonding capital draws the like-minded together (organized social capital). Groups vary in their tolerance of existing structures and may live out alternative forms, such as post-disaster community organization established as a break from centralized governance. Polarization (r) marks a firming up of 
Fig. 1. Regime transitions (based on Scheffer et al. 2002)

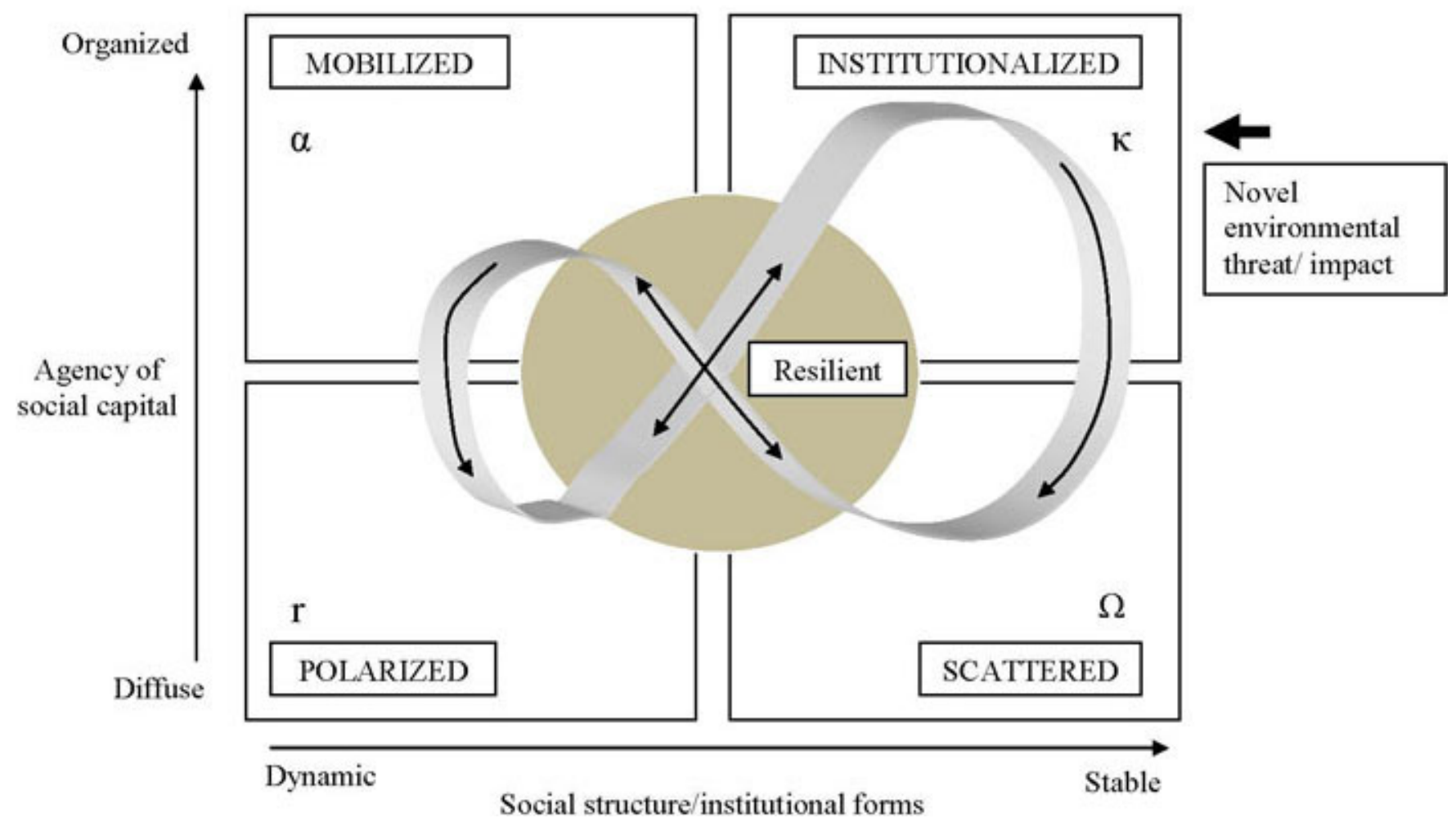

social capital positions and coalition building such that differences become fewer but more marked. This results in diffuse social capital and dynamic social relations with contradictory institutions potentially coexisting and an increased likelihood of conflict and backsliding towards scatter. If new institutions are built that better suit the values and risk preferences of emergent, dominant social actors, again under the influence of external/higher scales of power and interest, a new of phase of institutionalization $(\kappa)$ is established offering a new equilibrium between agency and structure symbolized in a new risk social contract, and indicated by changes in the application of technological as well as social organization, legislation, or policy.

Figure 1 presents these four idealized states in systems evolution. It draws analytical attention to underlying relationships between actors and institutional structures that channel movement in social capital and structural relations. Equally as informative are the gaps between these states, that is, the transitional periods in which structure and agency are mutable and outcomes are uncertain; backsliding, lock-in, jumping a state or smooth transition are all possibilities.

The speed and depth of movement from an institutionalized to a scattered state signifies the resistance/flexibility of the established regime and its sub-components. This includes degrees of control over development discourse and related tendencies for denial or cover-up of risk and loss that can result in organizational resistance even in the face of material threat, with potentially catastrophic implications for long-term sustainability, while maintaining regime stability in the near term (Handmer and Dovers 1996). Movement from scatter to mobilization states is a key moment in which science, religion, and other sources of opinion, and personalities, can shape the landscape of values going forward. Capacity to organize, which may to a large extent be historically 
determined, shapes the speed and cohesiveness of the transition from mobilized to polarized society. The transition from polarized to institutionalized states draws attention to the mechanisms through which emergent coalitions of interest and power formed during earlier phases can exert themselves and come to influence any new risk social contract and resultant regime. The "risk social contract" (Pelling 2011) describes the balance between rights and responsibilities that exists between dominant and subordinate actors, often but not always the state and citizenry, in society that helps legitimate existing governance regimes. Table 1 summarizes the qualities of agency and social structures for each state and transitional period.

As these four transitional periods indicate, there is no guarantee that each phase in this model will smoothly move into the next. Polarized politics may persist if no common approach can be negotiated or enforced from a position of authority. Scheffer et al. (2002) also suggest that rigidity traps can set in if there is too much stability in an institutionalized regime, whether through uncritical consensus or suppression of alternatives. This reduces flexibility, willingness, and ability to enter into new rounds of adaptation, and increases risk of catastrophic collapse. A solution is offered with an ideal state of resilience lying at the interface of all four domains in which there is active plurality of values set within a facilitating but not rigid set of institutions. This is an uncomfortable, perhaps unobtainable, state for political actors and those at risk, with increasing uncertainty and likely increased short-term costs coming with enhanced flexibility. Nevertheless, the notion of an idealized state is useful for comparing the experiences of different political regimes.

Building on the work of Scheffer et al. (2002) opens up many questions on the social and political dimensions of resilience and transformation. First, how easy is it for alternatives to emerge at different phases of this cycle? Under climate change it is especially important to be able to identify opportunities and constraints for adaptation following scientific warning of slow and difficult to "feel" change, as well as the identification of more immediate disaster threats or impacts (Beck 2009). Second, what does a resilient political-ecological system look like? Political ecology has spent much time analyzing the power dynamics lying behind material environmental and social change (Bryant and Bailey 1997); does the adaptive cycle model offer new insights? For example, can the model be used to reconstruct the pathways and behavior that have allowed certain ideas and behavior to grow or decline in the adaptive cycle of a regime? Third, where do flexibility and innovation emerge, and which interests control such processes? This requires not only assessing who is to benefit but also the basis upon which innovations or changes in social organization and structure are conferred legitimacy.

\section{APPLYING THE ADAPTIVE CYCLE ON MEXICO'S CARIBBEAN COAST}

The adaptive cycle will now be applied to frame an analysis of the position and capacity for resilience and transformation in two urban regimes. These centers, Mahahual and Playa del Carmen, are expanding and exposed to similar threats. They are at risk from climate change associated hazards, such as tropical storms, hurricanes, and heat waves, as well as more creeping risks of sea level rise and indirect effects that may affect the international tourism economy. These hazards interact with local environmental management challenges including solid waste management and sanitation, and development pressures causing the cutting of mangrove and disturbance of near-shore sedimentary cells. The Quintana Roo State Government, supported by Federal agencies, takes hurricane risk management seriously, and there is a good local record in early warning, evacuation, and speedy reconstruction. The most recent event, Hurricane Dean in 2007, caused limited economic impact, although Mahahual did receive a direct hit and was among the most damaged settlements providing an opportunity to research the post-disaster application of the adaptive cycle. In contrast, climate change was not a political priority in Quintana Roo at the time of research, though the hosting of the UNFCCC Conference of the Parties in Cancun in November 2010, has stimulated municipal climate change action plans in Cancun and Chetumal, and the drafting of a Quintana Roo wide policy.

Data were collected from interviews with leaders of social, environmental, and business associations, and where formal organization was absent among informal leaders. Following interviews, respondents were invited to town-level workshops to verify results and also as a vehicle for social actors to network. In both sites this was the first time social 
Table 1. The adaptive cycle states and transition: social agency and structural qualities

\begin{tabular}{lll}
\hline \hline Adaptive cycle phase & $\begin{array}{l}\text { Agency of social capital } \\
\text { (action and behavior) }\end{array}$ & $\begin{array}{l}\text { Social structure } \\
\text { (discourse and institutions) }\end{array}$ \\
\hline Institutionalized & $\begin{array}{l}\text { Agency reinforces and is aligned to dominant } \\
\text { social structures and institutions. Alternative } \\
\text { behavior is marginalized or excluded. }\end{array}$ & $\begin{array}{l}\text { Cohesive structure legitimates prevalent social } \\
\text { behavior. Alternative discourses and associated } \\
\text { institutions are marginalized or excluded. }\end{array}$
\end{tabular}

Transition Likelihood of transition to a new state is influenced by cultural norms determining the limits of risk and loss tolerance and denial, institutional resistance to change, and capacity to cope with risk and loss.
Scattered
Diffuse and diverse, social capital and behavior can break away from normalized routines and
Established institutions and discourse seen to positions. A space for alternatives to emerge or be formed
have failed in providing security or explaining risk. While these structures are still in place they are no longer reinforced by social agency initiating a crisis in structural reproduction

Transition New constellations of values emerge and compete for discursive dominance.
Mobilized
Social capital hardens around discrete value positions and specific coalitions of interest
Contradictory and supportive discourses and emerge. institutions coexist in overlapping emergent regimes.
Transition Historical and political contexts shape the speed of movement from a focus on the building of internal cohesion for diverse social groups and their associated institutions and discourses to mobilization and competition between competing values and behavior.
Polarized
Competition between alternative social groups
Fewer, but more forcefully argued differences is overt. New hierarchies or non-hierarchies arise.

Transition Negotiation or imposition of a new risk social contract

actors had met to discuss climate adaptation or mitigation.

The resulting data represent viewpoints from the perspective of civil society leaders and innovators. This is only a partial view but reflects a positive bias with civil society dependent upon social capital for its structure and most likely to be the arena from which alternative and critical discourses and behavior will arise. From this viewpoint, the properties of municipal governance that shape capacity for adaptation and mitigation are analyzed. Following this methodological note and background description for both sites we examine in turn the properties of structure and agency, with points of interaction noted. A discussion section begins to shape answers to the questions presented and provide reflection on the utility of the adaptive cycle as an analytical frame for revealing the power relations that influence pathways toward resilience and potential transformation. 


\section{Urban Profiles}

Mahahual is a pioneer settlement with a permanent population of about 1,000. Almost all are inmigrants from elsewhere in Quintana Roo, Mexico, and other countries. From 2008, Mahahual was conferred the status of Alcaldía and administered through a local council. The administrative region of Mahahual includes the tourism center with its beach properties, modern residential properties, and cruise ship terminal and several small satellite residential and farming communities, including an informal settlement located two kilometers away from the main center. As the economic base shifted from seasonal fishing to tourism, rapid in-migration and land speculation have changed the physical and social structure of the town. Few original families remain and these are a small minority compared to the immigrant population. The local economy experienced a boom since the construction of the cruise ship terminal. Hurricane Dean made a direct hit on Mahuhual in August 2007 with the subsequent closure of the cruise ship terminal until 2009 stalling the local economy which was then hit by the global economic downturn in the same year. The vivid memory of Hurricane Dean acted as a lens through which climate change and development were discussed. Our respondents reflect the boom/ pioneer town character of Mahahual and included eight individual entrepreneurs, three small and medium-sized business associations and three social organizations.

Playa del Carmen has a successful and growing economy based on international tourism and in 1994 became the capital of the newly created Municipality of Solidaridad. Since then, it has been claimed that Playa is the fastest growing urban center of Latin America, with an annual growth rate of over 20\% (Campos Cámara 2007). In 2005, its population exceeded 100,000 inhabitants. Playa has experienced direct hits from hurricanes. The worst challenge came in 2005 with Emily and Wilma a few months later. However, there were no fatalities and the town recovered very rapidly. In fact, following Wilma, the local tourist economy benefited from the relocation of tourists from Cancun which had been hit even harder. Local civil society has some maturity and this was reflected in the range of respondents who included five support associations for small and medium-sized businesses, six social, and four environmental local non-governmental organizations.

\section{Social Structure}

Strength in the dominant development and climate change risk discourse indicates the depth of structural legitimation and signification enjoyed by the contemporary regime, a regime reinforced through feedbacks from prevalent behavioral norms and only weakly challenged by very limited alternative development visions or action. Most respondents in both sites saw development in personal terms, that is, their aim was to improve individual or family quality of life, not to support collective action or public assets. This set a tight constraint for any transformational agenda and was a challenge for adaptation and mitigation which might be seen as public goods. The dominant social construction of climate change was seen as something "of global concern" and "out there", with only passing relevance to everyday life. Under the dominant discourse, inaction was appropriate and legitimate. Moreover, this discursive form made those few observed local investments in assets or behavioral change directed at adaptation or mitigation illegitimate for the mainstream; they were seen as benevolent but irrelevant or selfindulgent, and at best a niche ecotourism marketing tool. Inaction materially reinforced established value positions helping to maintain the discursive truth that local actors held little responsibility for acting on climate change. This was a problem seen as unfolding at the global scale, with global or at best national-scale actors responsible for responding.

In Mahahual, a pioneer settlement, a common sense of excitement and opportunity was directed by a desire to build the town without being dominated by mass tourism. A dominant sense of place presented Mahahual as an "open frontier" in which local residents had a central stake in shaping their own future, something that was less achievable in more established centers like Playa, which are already dominated by corporate interests. Despite this signifying resistance from the structures of domination, environmental concerns and responsibility for others remained marginal, conforming to more widespread discourses of development. Development for the majority in Mahahual meant the improvement of critical physical and social infrastructure and promotion of the local economy. Discursive construction of climate change associated it tightly to hurricane risk. This legitimated both a lack of focus on creeping climate change risk and options for climate change 
mitigation, despite potential opportunities that might come from a new green economy or related eco-tourism labeling. This was the case for individuals, businesses, and in the local development strategy. Furthermore, the presentation of hurricane risk as a development externality allowed responsibility for risk management to be pushed out and toward the Regional and Federal governments justifying local inaction. Information networks that might have been pathways for learning and spreading alternative visions and challenging discourse were informal and personalized but extensive, stretching to other parts of the state, Mexico, and overseas, and led, for example, to calls for a local civil protection body in local government. Climate change was not present even in local rhetoric despite some action on related agendas; for example, the Tourism Entrepreneurs Association of Costa Maya campaigned for investment in waste recycling.

In Playa, dominant development discourse also emphasized personal economic advancement. Here, however, it reflected the greater control enjoyed by the corporate private sector over the local economy, including ownership of most land. Respondent views indicated a strong sense of alienation of people from place with residents feeling they were in Playa to "make money", not to settle. This contrasted with the reality of life for economic migrants with many now living with their families for more than a decade and likely to stay for the long term. This disconnect between discourse and materiality of residence expressed itself in a lack of popular commitment to local or community activities and an unwillingness to take action that might hold corporate private sector or government actors to account. As one social development activist reported: "there is a lack of civic pride and identity with place. People do not care about the city or even their house and street". Respondents described the culture of Playa as embodying an extreme version of the American Dream, celebrating individualism and materialism, shortterm gain over long-term development. Alienation of individuals from society and place supported the dominant structures of domination, limiting capacity for the emergence of alternative visions let alone behavior.

Despite this dominant vision, some civil society leaders recognized individual responsibility for climate change. As one respondent put it, "We increasingly behave like machines. We need to go back to our community and our roots". Some recognized the need for a change in dominant values and consciousness as a basic prerequisite for responding to climate change and that climate change could be a vehicle to engage citizens and motivate them to hold the government and the wider, dominant development vision to account. In this logic, local adaptation and mitigation initiatives were supported as leverage points for existing social and environmental agendas. Some movement was reported in specific sectors, such as for example the drafting of a Sustainable Coastal Tourism plan, believed to be the first in Mexico to include guidance on development control for beach and mangrove management. Huge scope for mitigation in the hotel sector was recognized with minimal current use of alternative energy, water recycling, and waste management. Strategy for future adaptation included recognition of creeping and indirect risks, for example in calls for more local food production to provide both a diversification in livelihoods and reduce dependence on external markets. Information networks were well established and connected, for example, to environmental lawyers based in Cancun. Legal action had the potential to challenge dominant behavior and structures through the exercising of existing but often suppressed environmental legislation. Actions had prevented large-scale tourism developments on environmental grounds including X-Cacel, X-Cacelito and the Ultramar Doc. However, NGOs claimed the strategic value of these victories lay not in challenging the structures of domination and presenting alternative visions, but in showing that the application of environmental legislation would not constrain local economic growth. The dominant structures were pushed and shown to be flexible to accommodating challenge without modifying underlying goals or form: resilience as resistance.

\section{Agency and social capital}

The balance between social structures and social agency, with its organized forms of social capital, helps explain the cohesiveness of a governance regime and its position in the adaptive cycle. Following from the analysis of discourse as a way of revealing the social structures in a regime, aspects of social agency will now be examined. In both sites, trust became central in explaining the geometry of social relations. Trust was held most strongly in bonding ties of family or friendship, which served to perpetuate closed circuits of power while limiting 
the scope of organized resistance or communication of alternative values and discourses. Capacity for self-organization and access to new information and experiences that might facilitate social learning, innovation, and adaptation were constrained by these social capital formulations that were the very vehicles for the centralization of power and that maintained the prevalent structures of domination.

In Mahahual, community structures were weak with pervasive mistrust of social organization and its leadership, in business, social, and local government spheres alike. Low trust was partly explained by the diverse demographic base and individualized culture of this frontier settlement, with many immigrants and a small population base. The leader of a fishing cooperative reflected on the impact of low trust on the formation of his group: "we had to [hold] ... three meetings before we could elect a president. People tend to attack those who stand out from the rest [leaders]. They think one is looking for his own benefit". The combined influence of structures of legitimation and domination on organizing capacity was exemplified well by the residents of Km55, a satellite settlement with formal and informal land holdings in which one leader reported that "only 36 of 400 plots are occupied, the rest are held speculatively, this makes it hard to organize", another noted that "uncertainty about land titling is [causing delays] ..., for example, people will not put electricity in their lots until this is solved".

In Mahahual, post-Dean reconstruction did seem to open scope for transition away from the established institutionalized state, though movement was localized and short-lived, never threatening the overarching governance regime. One local business leader reported that:

\begin{abstract}
Before Dean I tried many times to create an association, but without Dean and all this easy money nobody paid much attention. All the ideas that I was proposing turned out to be right after Dean. Now people are starting to build a common culture because the ones who have stayed do not see this place only in terms of money.
\end{abstract}

Another respondent commented that:

After Dean one is starting to feel more solidarity. It is happening as in Cozumel, people there are building solidarity as a result in part of facing many hurricanes.
The temporary post-disaster weakening of state power opened the scope for more exaggerated forms of dominant individualized and short-term action, with examples of mangroves being illegally cleared. But for those seeing potential in collective action, post-Dean reconstruction also served as a common context for organizing. A sense that local civil society actors had a stake in shaping the future of Mahahual was reinforced by a search for alternative tourist markets during the 18 month closure of the cruise ship terminal. Some respondents also argued that Mahahual's recent Alcaldía status would open up new opportunities for collaboration with local government. The Alcadía was concerned with projecting itself as seeking to build partnerships with local civil society to support adaptation and mitigation initiatives, though none were observed or planned.

In Playa, civil society groups were present but tended to operate as top-down advocates or satellites to the government-corporate business policy making core (Manuel-Navarrete et al. 2011). One social development leader observed that "organizations are closed; they inform only staff and families, [and] there is little public communication about plans or opportunities". This reflected the lack of trust and individualized nature of Playa's American Dream culture, one where, as one respondent put it, there was "no culture for donations, public participation, or volunteerism". Perhaps because of competition between organizations, the strong personalities of entrepreneurial leaders and associations with municipal government, there were few examples of bridging capital collaboration across sectors. This is a particular challenge for building capacity for adaptation and mitigation which would benefit from civil society wide collaboration to lobby for, and implement, alternative development approaches.

Lack of capacity to develop advocacy coalitions to argue for alternative development from within civil society was exacerbated by constraints on institutional learning in municipal government. Constrained learning was a product of competitive politics, described as the tres años system. Elections held every three years caused the removal of sitting political leaders and the replacement of technical staff, so that maintaining the projects of an old regime was logistically and politically difficult. Perhaps worse, the minimal political differentiation between parties and candidates meant that alternatives were excluded while incremental transformation was also made difficult. In summary, achieving material impact on development was seen 
as only being achievable from inside the power core of government-private capital interest; outside this, while any view could be held, it was unlikely to have influence. This does not discount the possibility of local actor led reform, but no examples of this process and little capacity were observed with systemic features actively suppressing the emergence of alternatives. Elsewhere NGOs used climate change to promote preexisting agendas, for example in lobbying for greater investment in solid waste management. This was an instrumental and nonthreatening use of climate change by NGOs that successfully opened up policy space for environmental reform within the existing development discourse without challenging existing structures.

\section{DISCUSSION}

How well does the adaptive cycle help us to analyze the resilience or adaptive capacity of these two urban centers? Despite their differences in population and economy, disaster experience, and histories of municipal government, the adaptive cycle draws out well the rigidity trap that is being experienced in Mahahual and Playa, which is the same trap in which most urban governance regimes find themselves with regard to climate change. In both of these towns, the structures of governance are intact, including the institutions of the state at all scales, legislative authority, and the storylines that give meaning and identity and make sense of the dominant mode of development. This is despite their manifest failure, certainly at the municipal level, to recognize climate change as a policy concern beyond hurricane risk management.

Part of the internal contradiction of the structures of power revealed by the adaptive cycle is their ability to frame discourse and prevent conscientization (Freire 2000). As proposed by Freire (2000), conscientization describes learning that can enable the marginalized to perceive social, political, and economic contradictions, develop a critical awareness, and challenge oppressive elements of reality. This is an essential component in moving away from institutionalized positions. Freire was interested in the processes of conscientization as part of development. Our focus broadens to include those catalyzed by disaster or the creeping crisis of climate change. Evidence points to effective systemic processes blocking conscientization at the point of learning, exemplified by the dominant preference for maximizing personal economic wealth beyond aspirations for social or environmental aspects of well-being or sustainability, and organized resistance, observed by a lack of collective action and widespread distrust of social organizers. The result is a sense of lock-in with the institutionalized status quo generating feedback loops that support further entrenchment.

By closing down imagination, discussion of alternative values, and organization, dominant structures, and social agency simultaneously support and undermine resilience. Resilience is supported through capacity for small adjustment set within overall systems persistence, but undermined by the limited breadth of learning and experimentation, centralized power, and limited diversity of the economic base and legitimacy enjoyed in the current regime. The existence of such contradictions is not new to critiques of development or capitalism (Pelling et al. 2011), but with climate change such tensions become doubly significant and it is important that they are revealed through the emerging tools of climate science, such as the adaptive cycle heuristic.

Arguably some movement from the institutionalized state was observed in Mahahual post-Dean. Social agency did move away from established structures as residents became newly willing to organize during reconstruction. This could be presented as the brief opening of a subsystem that quickly moved to a scattered state and then slid back and was absorbed by the overarching institutionalized state. Scale at this point is important as an axis for considering the emergence of alternative narratives and action, even if temporary. In Playa, the institutionalized state entertained some diversity, for example in organized civil society lobby groups, but these were close to the center of power. Outside positions of influence, alternative values, and lived practices were rare, but could be found. The fact that these included actions to help build self-worth, pride and identity in place, reveals ongoing struggles over conscientization. This also flags a deeper challenge for the use of the adaptive cycle for social analysis in that systems need to be differentiated not only by scale or sector but also viewpoint. Normative positioning is difficult to escape when the object of analysis includes competing value systems and divergent material lifeworlds. 


\section{CONCLUSION}

Earlier theoretical discussions provoked three questions on the social and political dimensions of resilience. Our empirical work allows some tentative answers to be offered in conclusion.

First, does the adaptation cycle enable any better purchase on explaining the emergence and systems movement? The juxtaposition of structure and agency allowed some subtlety in the subsequent analysis which overcame a tendency to place sectors of activity (civil society, the state or private sector) or structure and agency in simple opposition. The interdependence of social structure and agency came through clearly in analysis and was highlighted as a challenge for transition and movement between states that might enable resilience. This is a useful contribution to our understanding of systems and shows the importance of including the multiple dimensions of power in analysis. No simple relationships between states were evident with backsliding and the opening of transitional subsystems observed.

Second, what does a resilient political-ecological system look like? Analysis from Mahahual and Playa suggests that resilience itself is a subjective quality and can be held differentially. Structureagency complexes were found to both generate and undermine resilience. Analytical judgments depend on the scale of the system of interest, but also on its goals expressed in discourse and materially, and these are derived from values which neither respondents nor the analyst can escape. Potentially there are as many ways of seeing and evaluating systems qualities as there are subjects and observers.

Third, where do flexibility and innovation emerge and how are these processes controlled? The systemic alienation of individuals was instrumental in supporting dominant structures through the production of a compliant citizenry and in part required a restriction in the direction, focus, and amount of innovation from the bottom up. The result was resistance to change within state-level institutions and a lack of individual responsibility combining to constrain systems flexibility and adaptive capacity.

The contradiction in resilience that generated rigidity and made transformation difficult in these social systems is likely to be common to many such systems. It marks a baseline from which to examine movement toward adaptation, over rigid forms of resilience. Rigidity in these cases goes beyond the common application of lock-in, which emphasizes ecologically derived feedback loops. Rather, explanatory focus was placed upon the ways in which agency deviated from, or more commonly, was instrumental in, purposeful acts that reinforced existing institutional structures. Observed deviations unfolded in marginalized or closed and temporary systems spaces always at a distance from centers of power. In risk management the distinction between forms of resilience that support rigidity or transformation can be seen in differences between those approaches that strengthen stability in the status quo, in which risk management is a tool for resisting stress and managing the expectations of those at risk, and those that champion innovation with the potential for change, in which risk management is a component of adaptive management and a tool for opening dialogue contributing to wider, inclusive forms of governance. The latter path is not easy for politicians with an eye on short-term stability, but as Handmer and Dovers (1996) warn, while rigidity may be more politically acceptable, it is also a pathway to potentially catastrophic systems collapse.

Responses to this article can be read online at: http://www.ecologyandsociety.org/voll6/iss2/art11/ responses/

\section{Acknowledgments:}

Research was supported by the UK Economic and Social Research Council, grant RES 062-23-0367.

\section{LITERATURE CITED}

Beck, U. 2009. World at risk. Polity Press, Cambridge, UK.

Bryant, R., and S. Bailey. 1997. Third world political ecology. Routledge, London, UK.

Campos Cámara, B.L. 2007. Procesos de urbanización y turismo en Playa del Carmen, Quintana Roo. Plaza y Valdés, Mexico. 
Chapin III, F. S., S. R. Carpenter, G. P. Kofinas, C. Folke, N. Able, W. C. Clark, P. Olsson, D. M. S. Smith, B. Walker, O. R. Young, F. Berkes, R. Biggs, J. M. Grove, R. L. Naylor, E. Pinkerton, W. Steffen, and F. J. Swanson. 2009. Ecosystem stewardship: sustainability strategies for a rapidly changing planet. Trends in Ecology and Evolution 25 (4):241-249.

Folke, C., T. Hahn, P. Olsson, and J. Norberg. 2005. Adaptive governance of social-ecological systems. Annual Review of Environment and Resources 30:441-473.

Freire, P. 2000. Education for critical consciousness. Continuum, New York, New York, USA.

Gelcich, S., T. P. Hughes, P. Olsson, C. Folke, O. Defeo, M. Fernández, S. Foale, L. H. Gunderson, C. Rodríguez-Sieker, M. Scheffer, R. Steneck, and J. C. Castilla. 2010. Navigating transformations in governance of Chilean marine coastal resources. Proceedings National Academy of Sciences, USA 107(39):16794-16799.

Giddens, A. 1984. The constitution of society: outline of the theory of structuration. Polity, Cambridge, UK.

Giddens, A. 2009. The politics of climate change. Polity, Cambridge, UK.

Handmer, J. W., and S. R. Dovers. 1996. A typology of resilience: rethinking institutions for sustainable development. Organization and Environment 9 (4):482-511

Harvey, D. 2010. The enigma of capital and the crisis of capitalism. Profile Books, London, UK.

Holling, C. S., L. H. Gunderson, and G. D. Peterson. 2002. Sustainability and panarchies. In L. H. Gunderson, and C. S. Holling, editors. Panarchy: understanding transformations in human and natural systems. Island, London, UK.

Hulme, M. 2009. Why we disagree about climate change. Cambridge University Press, Cambridge, UK.

Jerneck, A., and L. Olsson. 2008. Adaptation and the poor: development, resilience and transition. Climate Policy 8(2):170-182.
Manuel-Navarrete, D., M. Pelling, and M. Redclift. 2011, Critical adaptation to hurricanes in the Mexican Caribbean: development visions, governance structures, and coping strategies. Global Environmental Change A 21:249-258.

Nelson, D. R. 2009. Conclusions: transforming the world. In W. M. Adger, I. Lorenzoni, and K. L. O'Brien, editors. Adapting to climate change: thresholds, values, governance. Cambridge University Press, Cambridge, UK.

Pelling, M. 2011. Adaptation to climate change: from resilience to transformation. Routledge, London, UK.

Pelling, M., and C. Dill. 2010. Disaster politics: tipping points for change in the adaptation of sociopolitical regimes. Progress in Human Geography 34:21-37.

Pelling, M., C. High, J. Dearing, and D. Smith. 2007. Shadow spaces for social learning: a relational understanding of adaptive capacity to climate change within organizations. Environment and Planning A 40(4):867-884.

Pelling, M., D. Manuel-Navarrete, and M. Redclift. 2011. Climate change and the crisis of capitalism: a chance to reclaim self, society and nature. Routledge, London, UK.

Pritchard L., Jr., and S. E. Sanderson. 2002. The dynamics of political discourse in seeking sustainability. In L. H. Gunderson, and C. S. Holling, editors. Panarchy: understanding transformations in human and natural systems. Island, London, UK.

Scheffer, M., F. Westley, W. A. Brock, and M. Holmgren. 2002. Dynamic interaction of societies and ecosystems - linking theories from ecology, economy and sociology. In L. H. Gunderson, and C. S. Holling, editors. Panarchy: understanding transformations in human and natural systems. Island, London, UK.

Scott, J. 2001. Power. Polity, Cambridge, UK. 